\title{
A mixed treatment comparison to compare the efficacy and safety of botulinum toxin treatments for cervical dystonia
}

\author{
Yi Han ${ }^{1}$ - Andrea L. Stevens ${ }^{1}$ - Khashayar Dashtipour ${ }^{2}$. Robert A. Hauser ${ }^{3}$. \\ Zoltan Mari $^{4}$
}

Received: 5 November 2015/Revised: 23 January 2016/Accepted: 25 January 2016/Published online: 25 February 2016 (c) The Author(s) 2016. This article is published with open access at Springerlink.com

\begin{abstract}
A systematic pair-wise comparison of all available botulinum toxin serotype A and B treatments for cervical dystonia (CD) was conducted, as direct head-to-head clinical trial comparisons are lacking. Five botulinum toxin products: Dysport $^{\circledR}$ (abobotulinumtoxinA), Botox ${ }^{\circledR}$ (onabotulinumtoxinA), Xeomin ${ }^{\circledR}$ (incobotulinumtoxinA), Prosigne ${ }^{\circledR}$ (Chinese botulinum toxin serotype A) and Myobloc ${ }^{\circledR}$ (rimabotulinumtoxinB) have demonstrated efficacy for managing $\mathrm{CD}$. A pair-wise efficacy and safety comparison was performed for all toxins based on literature-reported clinical outcomes. Multi-armed randomized controlled trials (RCTs) were identified for inclusion using a systematic literature review, and assessed for comparability based on patient population and efficacy outcome measures. The Toronto Western Spasmodic Torticollis Rating Scale (TWSTRS) was selected as the efficacy outcome measurement for assessment. A mixed treatment comparison (MTC) was conducted using a Bayesian hierarchical model allowing indirect comparison of the interventions. Due to the limitation of available clinical data, this study only investigated the main effect of toxin treatments without explicitly considering potential confounding factors such as gender and formulation
\end{abstract}

Yi Han

yi.han@wg-group.com

1 WG Consulting, 200 Fifth Avenue, New York, NY 10010, USA

2 Faculty of Medical Offices, School of Medicine, Loma Linda University, 11370 Anderson, Suite B-100, Loma Linda, CA 92354, USA

3 Health Byrd Institute, University of South Florida, 4001 E. Fletcher Ave, 6th Floor, Tampa, FL 33613, USA

4 School of Medicine, Johns Hopkins University, 600 N. Wolfe Street, Meyer 6-181B, Baltimore, MD 21287, USA differences. There was reasonable agreement between the number of unconstrained data points, residual deviance and pair-wise results. This research suggests that all botulinum toxin serotype A and serotype B treatments were effective compared to placebo in treating $\mathrm{CD}$, with the exception of Prosigne. Based on this MTC analysis, there is no significant efficacy difference between Dysport, Botox, Xeomin and Myobloc at week four post injection. Of the adverse events measured, neither dysphagia nor injection site pain was significantly greater in the treatment or placebo groups.

Keywords Cervical dystonia - Botulinum toxin . TWSTRS · Mixed treatment comparison

\section{Introduction}

Cervical dystonia (CD), formerly referred to as spasmodic torticollis, is a condition characterized by simultaneous and sustained contractions of both agonist and antagonist muscles of the neck [1]. The majority of patients complain of pain, which is not a common feature of other focal dystonias [1]. Head rotation (torticollis) is common, but head tilt (laterocollis), neck extension (retrocollis) and flexion (anterocollis) may also occur, often in combination [2]. $\mathrm{CD}$ is the most common type of focal dystonia encountered in neurological practice, with an estimated prevalence of 57 per million in Europe [3], or as much as $0.4 \%$ of the total population of the United States [4-6]. While there is a need for more accurate population-based epidemiology studies of $\mathrm{CD}$, this prevalence rate was confirmed by Defazio et al. in a 2012 review article [7].

Botulinum toxin (BoNT), a neurotoxin produced by the bacterium Clostridium botulinum, causes impairment of neuromuscular transmission leading to flaccid paralysis [8]. 
Intramuscular injections of BoNT have been shown to be efficacious and well tolerated when used to treat CD [9$12]$, and are therefore recommended as first-line therapy by current treatment guidelines [13, 14].

Two distinct serotypes of BoNT are available in clinical practice, and currently various different formulations of serotypes A and B are being used for the treatment of dystonia. Five BoNT products are available in various countries for the management of CD; Dysport ${ }^{\circledR}$ (abobotulinumtoxinA), Botox ${ }^{\circledR}$ (onabotulinumtoxinA), Xeomin ${ }^{\circledR}$ (incobotulinumtoxinA), Prosigne $^{\circledR}$ (Chinese botulinum toxin serotype A) and Myobloc $^{\circledR}$ (rimabotulinumtoxinB) [15]; however, there are limited data available to show a head-to-head comparison of these treatments in randomized clinical trials (RCT). It is unrealistic to expect that head-to-head RCT data will be available for all treatments, as clinical trials are expensive to conduct. In addition, the clinical and scientific values of such direct pair-wise comparisons are often questioned, due to trial design issues, and companies are reluctant to fund head-tohead comparisons of products likely to show similar efficacy. Importantly, with BoNT treatment of $\mathrm{CD}$, there is a dosing comparability issue that is not easily resolved [16].

Placebo-controlled studies have investigated the efficacy and safety of BoNTs, demonstrating a significant improvement from baseline in outcome scores for all treatments of interest, with similar safety profiles [10-12, 16-19]. Equivalent efficacy of Dysport to Botox has been demonstrated directly in two multicenter, double-blind, randomized studies in blepharospasm and CD, respectively [9, 20, 21]. Head-to-head comparisons have also demonstrated Myobloc to be non-inferior to Botox [16, 19], and Prosigne to have equivalent efficacy, safety, and tolerability as Botox [22]. Data from placebo controlled trials utilizing different treatments can be used in statistical analyses, allowing the data to be combined to compare and contrast their efficacy and safety benefits.

Meta-analysis is a statistical approach where direct clinical data from multiple sources can be combined to compare the efficacy and safety of two treatments [23], where

- For a large proportion of health interventions, there is no direct evidence that relates the interventions to the health outcome [24],

- Direct information exists on a specific treatment comparison, but does not provide enough information for a substantial statistical analysis. We then need to 'borrow strength' from indirect comparisons [25],

- No single treatment comparison is of specific interest; instead there is a need to simultaneously compare [26], or even rank, several treatments [27, 28].

The mixed treatment approach extends traditional metaanalysis to include indirect comparisons using hierarchical Bayesian methods, meaning multiple treatments can be compared in a single analysis [23]. This allows the efficacy and safety outcomes of numerous RCTs for multiple treatments to be compared head to head, potentially negating the need for additional RCTs and the associated complications and expense. This research was conducted to provide a systematic pair-wise comparison of all available BoNT serotype A and B treatments for CD, in light of the lack of direct head to head clinical trial data. A pair-wise efficacy comparison was performed for Dysport, Botox, Xeomin, Prosigne and Myobloc based on literature-reported clinical outcomes.

\section{Methods}

\section{Search strategy and selection criteria}

A search for multi-armed randomized controlled trials (RCTs) involving Dysport, Botox, Xeomin, Prosigne and Myobloc was conducted using several databases (Embase, Medline and Medline (R) In-Process). Each database was searched from inception to February 2014 and with no restriction on the language of the papers. The search was kept particularly broad with search terms on Botulinum toxin A, Botulinum toxin B, CD, cervical dystonia, TWSTRS, Toronto Western Spasmodic Torticollis Rating Scale, and a filter for randomized controlled trials was used in order to increase sensitivity.

\section{Inclusion criteria}

Only full-published reports of RCTs including patients affected by CD were considered; letters and abstracts were excluded. Only RCTs with TWSTRS measured as primary or secondary endpoints were included.

\section{Exclusion criteria}

RCTs studying disease areas other than CD or having as primary or secondary endpoint measures other than TWSTRS were excluded. Also studies comparing other interventions in $\mathrm{CD}$ were excluded.

\section{Interventions}

The intervention of at least one study group included one of the following drugs and dosing regimens in clinical use: Dysport, Botox, Xeomin, Prosigne and Myobloc.

\section{Efficacy outcome measures}

The Toronto Western Spasmodic Torticollis Rating Scale (TWSTRS) total score was selected as the efficacy 
outcome measurement for assessment [29]. The TWSTRS is a validated CD scale that captures the clinical features of $\mathrm{CD}$, and includes a videotape protocol such that all patients are viewed in a standardized fashion [29]. The TWSTRS is comprised of 3 subscales: severity, disability, and pain, each of which is scored independently. The total of these three comprises the TWSTRS total score, which is scored from $0-87$ (best to worst). It is worth mentioning that the Tsui score is also used in some clinical studies. However, the Tsui score is not validated in the same manner as the TWSTRS, and its relative simplicity means that several features of $\mathrm{CD}$, such as pain or disability, are not covered. There are also no clear criterion definitions for the Tsui score ratings of "mild", "moderate" and "severe" [30]. These factors make the Tsui scale unsuitable for MTC analysis.

\section{Safety outcome measure}

BoNT products are well tolerated and safe with proper injection into a target site. Common adverse effects ( $>10 \%$ frequency) include excessive muscle weakness, injection site pain, dry mouth, dysphagia, and fatigue. From a clinical perspective, the two most common clinically relevant adverse events, due to BoNT injections, are related to unwanted weakness. Injecting too much toxin in a particular area of the neck can cause weakness, leading to abnormal head positions or limitations in neck range of motion. Moreover, toxins can diffuse beyond the confines of injected muscles, potentially causing dysphagia due to weakness of swallowing muscles, especially when anterior neck muscles are injected [31]. Dysphagia can be uncomfortable, may necessitate a change in diet, and can lead to aspiration. Another common adverse event is injection site pain. This is usually transient and resolves in minutes to days. Many factors can potentially contribute to injection site pain including injection technique, type and size of needle used, volume and location of injection, and make-up and $\mathrm{pH}$ of the toxin and its associated constituents [32, 33]. To aid healthcare professionals in the correct evaluation of safety profiles for different toxin products, data was collected from these clinical studies for all reported major adverse events.

\section{Statistical analysis}

A mixed treatment comparison (MTC) was conducted using a Bayesian hierarchical model allowing indirect comparison of the efficacies of the interventions. MTC is a generalization of standard meta-analysis for pair-wise trials, to a simultaneous analysis of multiple pair-wise comparisons [34], for example, interventions $\mathrm{A}, \mathrm{B}$ and $\mathrm{C}$. Given the network of direct comparisons across the range of interventions, indirect estimates can be obtained for $d_{\mathrm{PA}}$, $d_{\mathrm{PB}}, d_{\mathrm{AB}}, d_{\mathrm{BC}}$, and $d_{\mathrm{PC}}$ (Fig. 1) where $\mathrm{P}$ stands for placebo. Given the mathematical relationships between the true underlying estimates of the different comparisons in the network, we have both direct and indirect evidence available for all the pair-wise comparisons, except for the BC comparisons (only indirect evidence) and the AC comparisons (only direct evidence). Hence, the advantages of the simultaneous analysis with MTC are that (1) estimates for indirect comparisons are obtained, and (2) indirect comparisons can support evidence for direct estimates [35].

To explicitly account for effects due to heterogeneity from different trials, a random effect MTC method was used incorporating the following formula:

Let $y_{i j}$ be the observed efficacy of treatment $j$ in the $i$ th study. It can be considered as a random observation from normal distribution centered at $Y_{i j}$ and $Y_{i j}$ be the unobserved mean efficacy with variance $\sigma_{i j}$. $Y_{i j}$ can be further expressed as the sum of baseline treatment effect $\mu_{i b}$ and efficacy differential $\delta_{i j b}$. Study level efficacy differential is a random outcome drawn from normal distribution centered at true efficacy differential $\Delta_{j b}$. From coherence assumption, pair-wised efficacy differential can be estimated indirectly through $\Delta$.

$y_{i j} \sim N\left(Y_{i j}, \sigma_{i j}\right)$

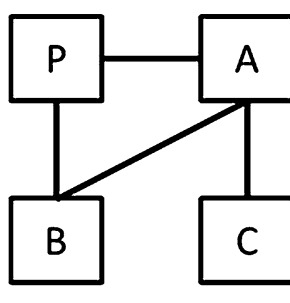

$$
\begin{aligned}
& d_{P A}=d_{P B}-d_{A B} \\
& d_{P B}=d_{P A}+d_{A B} \\
& d_{A B}=d_{P B}-d_{P A}
\end{aligned}
$$

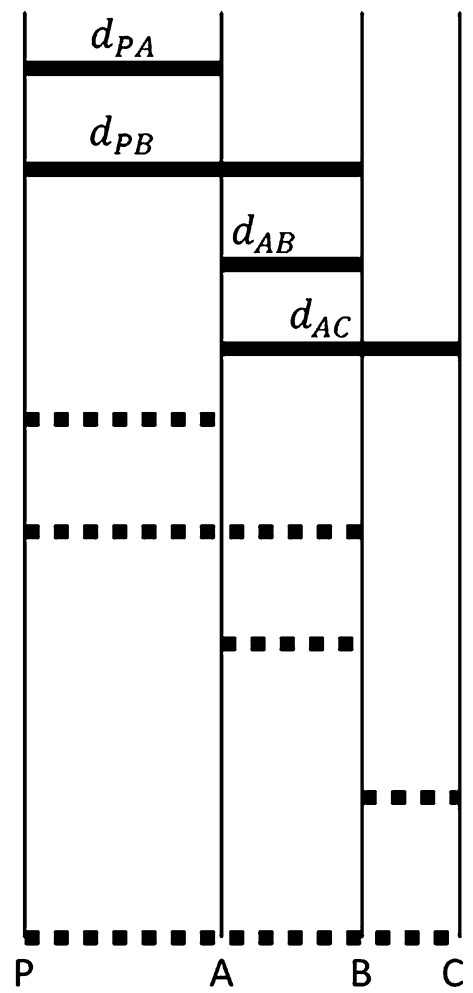

Fig. 1 Diagram representing the network of studies reflecting mixed treatment comparisons of $\mathrm{PA}$ trials, $\mathrm{PB}$ trials, $\mathrm{AB}$ trials, and $\mathrm{AC}$ trials (adapted from Jansen) [23] 
Fig. 2 MTC PRISMA Flow Diagram (adapted from Moher et al.) [36]
$Y_{i j}=\mu_{i b}+\delta_{i j b}(j \neq b)$

$\delta_{i j b} \sim N\left(\Delta_{j b}, \sigma\right)$

$\Delta_{j k}=\Delta_{j b}-\Delta_{k b}(j, k \neq b)$

Adverse events were modeled as a binominal distribution where the number of patients with a specific adverse event in trial $i$ treated with toxin $j$ is defined by $p_{i j}$ and $N_{i}$, the rate of adverse event and sample size for treatment $j$ in trial $i$ :

$n_{i j}=\operatorname{Bin}\left(p_{i j}, N_{i}\right)$

Logit transformation of $p_{i j}$ will be treated as a random variable with normal distribution. Relative safety against placebo was measured using the logarithm of odds ratio (LOR), where a positive number represents an increased risk.

\section{Results}

A total of 11 RCTs were identified through a systematic literature review carried out according to PRISMA (preferred reporting items for systematic reviews and metaanalyses) guidelines [36], providing data on 1295 participants. The process for selection and exclusion of studies is detailed in Fig. 2.

Table 1 summarizes the study characteristics of the trials included in the analysis.

Four trials compared Myobloc vs. placebo, two trials compared Dysport vs. placebo, one trial compared Xeomin vs. placebo, one trial compared Dysport vs. Botox, one trial compared Prosigne vs. Botox and two trials compared Myobloc vs. Botox. In this study, we focused our 
Table 1 Characteristics of included studies

\begin{tabular}{|c|c|c|c|c|c|}
\hline Publications & Interventions & Endpoints & Study design & $\begin{array}{l}\text { Number } \\
\text { randomized }\end{array}$ & $\begin{array}{l}\text { Treated } \\
\text { patients }\end{array}$ \\
\hline $\begin{array}{l}\text { Comella } \\
\text { J Neurological } \\
\text { Sciences } 2011\end{array}$ & $\begin{array}{r}\text { Xeomin } \\
120 \mathrm{U} \\
\text { Xeomin } \\
240 \mathrm{U}\end{array}$ & $\begin{array}{l}\text { Change from baseline to week } 4 \text { on } \\
\text { the TWSTRS total score }\end{array}$ & $\begin{array}{l}\text { Prospective, double-blind, randomized, } \\
\text { placebo-controlled, multicenter } \\
\text { clinical trial in botulinum toxin- } \\
\text { treated or toxin-naïve CD patients }\end{array}$ & 233 & $\begin{array}{l}78 \\
81\end{array}$ \\
\hline $\begin{array}{l}\text { Truong } \\
\text { Movement Disorders } \\
2005\end{array}$ & $\begin{array}{r}\text { Dysport } \\
500 \mathrm{U}\end{array}$ & $\begin{array}{l}\text { Change in TWSTRS total score at } \\
\text { week } 4 \text { compared with baseline }\end{array}$ & $\begin{array}{l}\text { Prospective, double-blind, randomized, } \\
\text { placebo-controlled, multicenter } \\
\text { clinical trial }\end{array}$ & 80 & 37 \\
\hline $\begin{array}{l}\text { Truong } \\
\text { Parkinsonism and } \\
\text { Related Disorders } \\
2010\end{array}$ & $\begin{array}{r}\text { Dysport } \\
500 \mathrm{U}\end{array}$ & $\begin{array}{l}\text { Change from baseline in the } \\
\text { TWSTRS severity, disability, and } \\
\text { pain subscale scores at week } 4 \\
\text { after the start of each treatment } \\
\text { cycle }\end{array}$ & $\begin{array}{l}\text { Randomized, } \\
\text { double-blind study to investigate the } \\
\text { efficacy and safety of intramuscular } \\
\text { admin-istration of Dysport compared } \\
\text { to placebo for the treatment of CD }\end{array}$ & 116 & 55 \\
\hline $\begin{array}{l}\text { Ranoux } \\
\text { JNNP } 2002\end{array}$ & $\begin{array}{l}\text { Botox } 100 \mathrm{U} \\
\text { Dysport } \\
500 \mathrm{U}\end{array}$ & $\begin{array}{l}\text { Change in the TWSTRS pain scale } \\
\text { score between baseline and } \\
\text { control visit }\end{array}$ & $\begin{array}{l}\text { Double blind, randomised, three period } \\
\text { cross over study }\end{array}$ & 54 & 51 \\
\hline $\begin{array}{l}\text { Quagliato } \\
\text { Clinical } \\
\text { Neuropharmacology } \\
2010\end{array}$ & $\begin{array}{l}\text { Botox } 100 \mathrm{U} \\
\text { Prosigne } \\
100 \mathrm{U}\end{array}$ & $\begin{array}{l}\text { Change of the } \\
\text { TWSTRS scores between the } \\
\text { baseline and control visits }\end{array}$ & $\begin{array}{l}\text { Prospective, randomized, double-blind } \\
\text { study to compare Botox and Prosigne } \\
\text { in the treatment of cervical dystonia }\end{array}$ & 24 & 24 \\
\hline $\begin{array}{l}\text { Kaji } \\
\text { Brain and Nerve } 2013\end{array}$ & $\begin{array}{c}\text { Myobloc } \\
2500 \mathrm{U} \\
\text { Myobloc } \\
5000 \mathrm{U} \\
\text { Myobloc } \\
10,000 \mathrm{U}\end{array}$ & $\begin{array}{l}\text { Change in TWSTRS total score at } \\
4 \text { weeks post dose from baseline }\end{array}$ & $\begin{array}{l}\text { Single-dose, placebo-controlled, } \\
\text { double-blind, dose-response study of } \\
\text { NerBloc }{ }^{\circledR} \text { (Myobloc) in patients with } \\
\text { cervical dystonia }\end{array}$ & 133 & 98 \\
\hline $\begin{array}{l}\text { Brashear } \\
\text { Neurology } 1999\end{array}$ & $\begin{array}{l}\text { Myobloc } \\
5,000 \mathrm{U} \\
\text { Myobloc } \\
10,000 \mathrm{U}\end{array}$ & TWSTRS total score at week 4 & $\begin{array}{l}\text { 16-week, randomized, multicenter, } \\
\text { double-blind, placebo-controlled trail } \\
\text { in type A-responsive patients with } \\
\text { CD }\end{array}$ & 109 & $\begin{array}{l}36 \\
37\end{array}$ \\
\hline $\begin{array}{l}\text { Brin } \\
\text { Neurology } 1999\end{array}$ & $\begin{array}{l}\text { Myobloc } \\
10,000 \mathrm{U}\end{array}$ & TWSTRS total score at week 4 & $\begin{array}{l}\text { 16-week, double-blind, placebo- } \\
\text { controlled trial of BoNT/B in type } \\
\text { A-resistant patients with CD }\end{array}$ & 77 & 39 \\
\hline $\begin{array}{l}\text { Pappert } \\
\text { Movement Disorders } \\
2008\end{array}$ & $\begin{array}{l}\text { Botox } 150 \mathrm{U} \\
\text { Myobloc } \\
10,000 \mathrm{U}\end{array}$ & $\begin{array}{l}\text { Change in TWSTRS from baseline } \\
\text { to week } 4 \text { post-injection }\end{array}$ & $\begin{array}{l}\text { International, multi-center, double- } \\
\text { blind, randomized, comparator study }\end{array}$ & 111 & $\begin{array}{l}55 \\
56\end{array}$ \\
\hline $\begin{array}{l}\text { Comella } \\
\text { Neurology } 2005\end{array}$ & $\begin{array}{l}\text { Botox } 250 \mathrm{U} \\
\text { Myobloc } \\
10,000 \mathrm{U}\end{array}$ & $\begin{array}{l}\text { Change in total TWSTRS score and } \\
\text { change in subscale TWSTRS } \\
\text { scores at maximal efficacy (week } \\
\text { 4) }\end{array}$ & $\begin{array}{l}\text { Randomized, double-blind, parallel- } \\
\text { arm study }\end{array}$ & 139 & $\begin{array}{l}74 \\
65\end{array}$ \\
\hline $\begin{array}{l}\text { Lew } \\
\text { Neurology } 1997\end{array}$ & $\begin{array}{l}\text { Myobloc } \\
2,500 \mathrm{U} \\
\text { Myobloc } \\
5,000 \mathrm{U} \\
\text { Myobloc } \\
10,000 \mathrm{U}\end{array}$ & $\begin{array}{l}\text { TWSTRS-total score at } 4 \text { weeks } \\
\text { following study drug } \\
\text { administration }\end{array}$ & $\begin{array}{l}\text { Randomized, multicenter, double- } \\
\text { blind, placebo-controlled, four-arm, } \\
\text { parallel-group outpatient study }\end{array}$ & 122 & $\begin{array}{l}31 \\
31 \\
30\end{array}$ \\
\hline
\end{tabular}

investigation on efficacy measured by the change in TWSTRS score 4 weeks post injection time. If standard deviations for week four TWSTRS score changes were not reported for a trial arm, the largest reported standard deviation of baseline or week four in that arm was used. For studies which only reported median and range values, mean and standard deviation was calculated based on the methods described in Hozo et al. [37]. In cases where no variance information was disclosed, the largest variances within the selected studies were used by default. There was reasonable agreement between the number of unconstrained data points, residual deviance and pair-wise results, suggesting a coherent network. The network of studies for each efficacy and safety outcome measure is shown in Figs. 3, 4 and 5. 


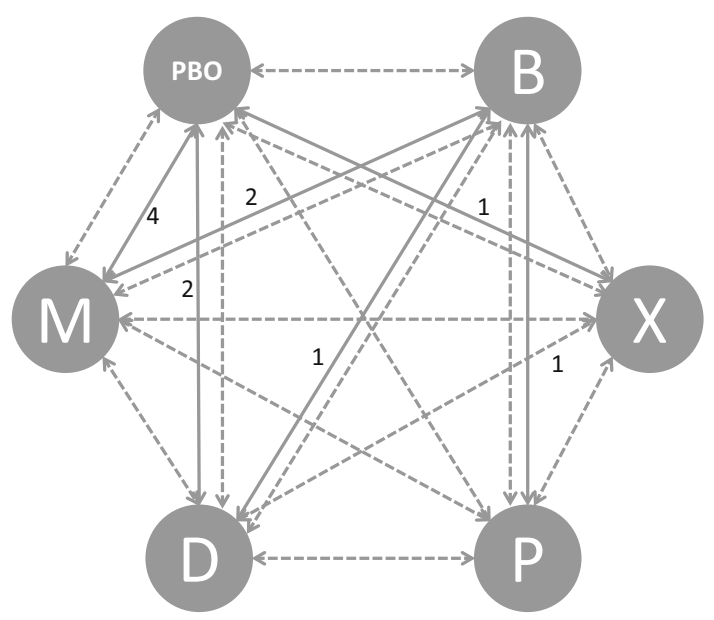

Fig. 3 TWSTRS PAIN and dysphagia network ( $P B O$ placebo, $B$ botox, $X$ xeomin, $P$ prosigne, $D$ dysport and $M$ myobloc)

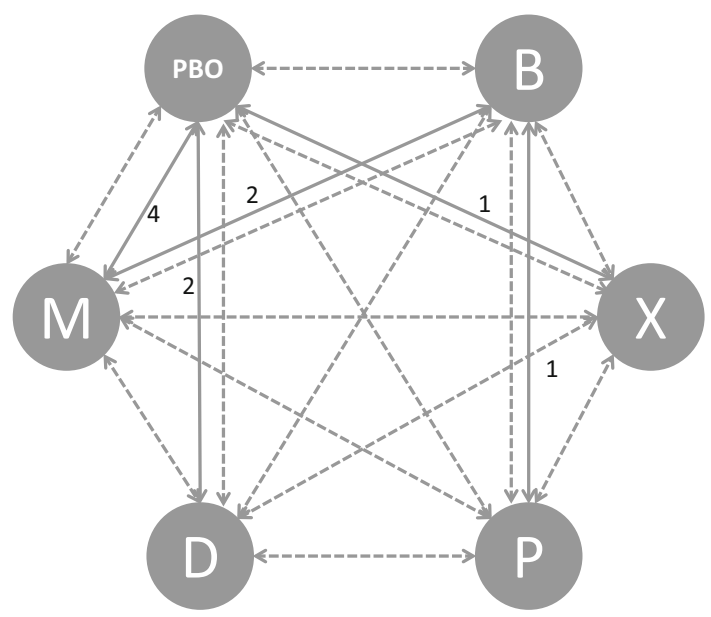

Fig. 4 TWSTRS total, disability and severity network ( $P B O$ placebo, $B$ botox, $X$ xeomin, $P$ prosigne, $D$ dysport, $M$ myobloc)

Numbers correspond to the number of studies compared within each part of the network.

The results of the MTC are shown in Table 2 and Fig. 6.

As shown in Table 2, all toxin treatments, apart from Prosigne, demonstrated a similar range of efficacy relative to placebo. Excluding Prosigne, the median TWSTRS total score improvements over placebo are within a range of $(-5.78,-8.22)$, with the sub-scale efficacy ranges being even narrower, as expected. The trends of efficacy measures are consistent with product label information and FDA marketing authorization. The median and $95 \%$ confidence interval for each toxin are shown in the forest plots (Fig. 6).

MTC analysis clearly demonstrated that BoNTs Dysport, Botox, Xeomin and Myobloc are more efficacious in managing $\mathrm{CD}$ when compared with placebo. However, there is no statistically significant performance difference

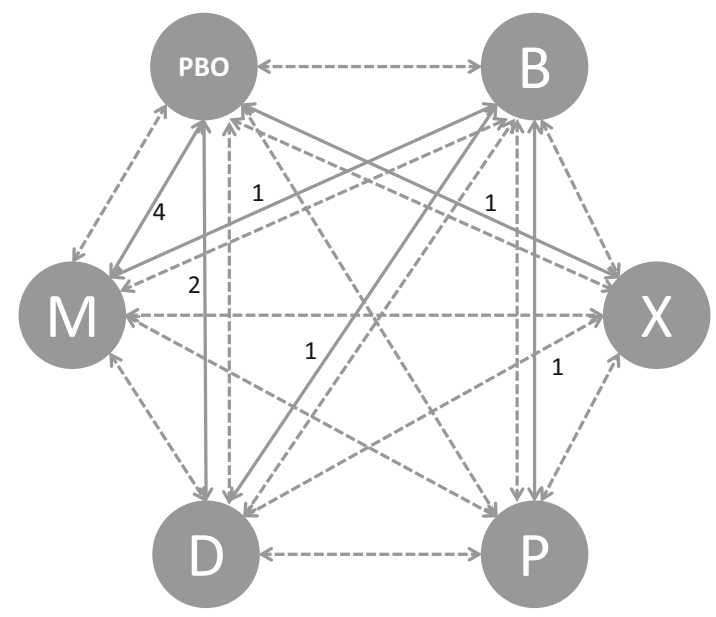

Fig. 5 Injection site pain network ( $P B O$ placebo, $B$ botox, $X$ xeomin, $P$ prosigne, $D$ dysport, $M$ myobloc)

among these toxins. Prosigne efficacy could not be confirmed because the data was extracted from a single study in which the outcomes deviated significantly compared with other published work.

Safety data reporting is not systematic in the public domain. Within the included journal articles from this systematic literature review, a sufficient number of studies were identified with data supporting analysis on the adverse events dysphagia and injection site pain. The analysis results are shown in Table 3, with forest plots to graphically depict the median Log Odds Ratio (LOR) and its $95 \%$ confidence interval (Fig. 7).

Similar to the trends observed in the efficacy comparison, the Prosigne data showed too much variance to draw reliable conclusions. For the other toxins included in this study, all $95 \%$ confidence intervals were overlapping. This is a clear indication that these toxins do not have a statistically significant different incidence rate for the adverse events under investigation; dysphagia and injection site pain. It is also interesting to see that for injection site pain, the rates of adverse events from toxin treatment were not different from placebo at the $95 \%$ confidence level.

\section{Discussion}

This is the first reported mixed treatment comparison of five BoNT treatments: Dysport, Botox, Xeomin, Myobloc and Prosigne, for the treatment of $\mathrm{CD}$. Based on the comprehensive systematic literature review and Bayesian hierarchical model mixed treatment comparison, this research suggests that BoNT treatments Dysport, Botox, Xeomin and Myobloc were effective compared to placebo in the treatment of $\mathrm{CD}$ as measured by the Toronto Western Spasmodic Torticollis Rating Scale total score at week four 
Table 2 Relative efficacy measured by median TWSTRS subscale score 4 weeks post injection

\begin{tabular}{|c|c|c|c|c|c|c|c|c|}
\hline \multirow{2}{*}{$\begin{array}{l}\text { Change at } 4 \text { weeks } \\
\text { BoNT }\end{array}$} & \multicolumn{2}{|c|}{ TWSTRS total } & \multicolumn{2}{|c|}{ TWSTRS severity } & \multicolumn{2}{|c|}{ TWSTRS disability } & \multicolumn{2}{|c|}{ TWSTRS pain } \\
\hline & Median & $95 \% \mathrm{CI}$ & Median & $95 \% \mathrm{CI}$ & Median & $95 \% \mathrm{CI}$ & Median & $95 \% \mathrm{CI}$ \\
\hline Botox & -5.779 & $-9.222,-2.399$ & -2.007 & $-3.726,-0.2261$ & -1.784 & $-3.293,-0.3679$ & -1.164 & $-2.419,0.0401$ \\
\hline Dysport & -7.761 & $-11.43,-4.195$ & -3.439 & $-4.938,-1.687$ & -2.161 & $-3.536,-0.5743$ & -2.554 & $-3.777,-1.392$ \\
\hline Xeomin & -8.215 & $-10.97,-5.352$ & -2.645 & $-4.133,-1.219$ & -3.146 & $-4.318,-2.029$ & -2.222 & $-3.36,-1.084$ \\
\hline Myobloc & -7.221 & $-9.535,-4.91$ & -2.383 & $-3.451,-1.138$ & -2.007 & $-2.962,-1.119$ & -2.276 & $-3.184,-1.408$ \\
\hline Prosigne & -3.645 & $-17.31,9.059$ & -1.972 & $-7.483,3.23$ & -0.6752 & $-5.357,3.448$ & -0.6075 & $-4.761,3.393$ \\
\hline
\end{tabular}

Fig. 6 Forest plots detailing the efficacy results of the MTC
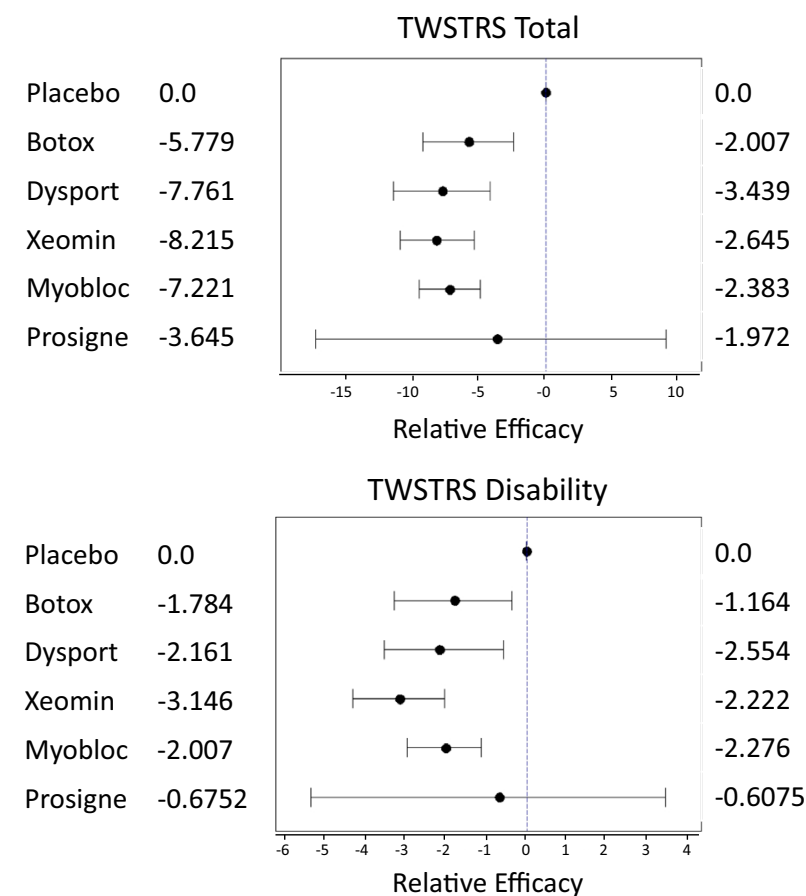

TWSTRS Severity

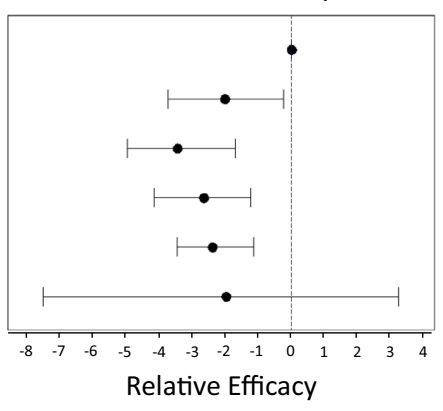

TWSTRS Pain

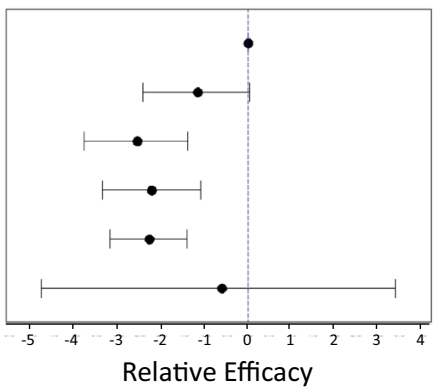

Table 3 Adverse event MTC results

\begin{tabular}{|c|c|c|c|c|c|c|}
\hline \multirow[t]{2}{*}{ Log odds ratio (LOR) } & \multicolumn{3}{|c|}{ Dysphagia } & \multicolumn{3}{|c|}{ Injection site pain } \\
\hline & Median & $95 \%$ CI low & $95 \%$ CI high & Median & $95 \%$ CI low & $95 \%$ CI high \\
\hline Botox & 1.012 & -0.3997 & 2.855 & 1.076 & -0.6695 & 3.065 \\
\hline Dysport & 2.212 & 0.8621 & 4.108 & 0.9522 & -0.01974 & 2.016 \\
\hline Xeomin & 2.086 & 0.347 & 4.349 & 0.1427 & -1.123 & 1.611 \\
\hline Myobloc & 2.144 & 1.116 & 3.818 & 0.2664 & -0.5163 & 1.027 \\
\hline Prosigne & 1.293 & -1.264 & 4.366 & -2.238 & -5.726 & 1.417 \\
\hline
\end{tabular}

Incidence of dysphagia and injection site pain measured at 4 weeks post injection

post-injection. Moreover, based on this MTC analysis, there is no significant efficacy difference between Dysport, Botox, Xeomin and Myobloc at week four post-injection. Prosigne data was inconsistent with other evidence included in this analysis. It is not possible to draw meaningful conclusions for the efficacy of Prosigne given the large variance of the model estimates. The advantage of this Bayesian MTC method, in comparison with traditional pair-wise meta-analyses, is that a larger range of data is taken into account in one single analysis. Moreover, the MTC approach includes the ability to compute the relative efficacy of each treatment without breaking trial 
Fig. 7 Forest plots detailing the MTC results for adverse events dysphagia and injection site pain

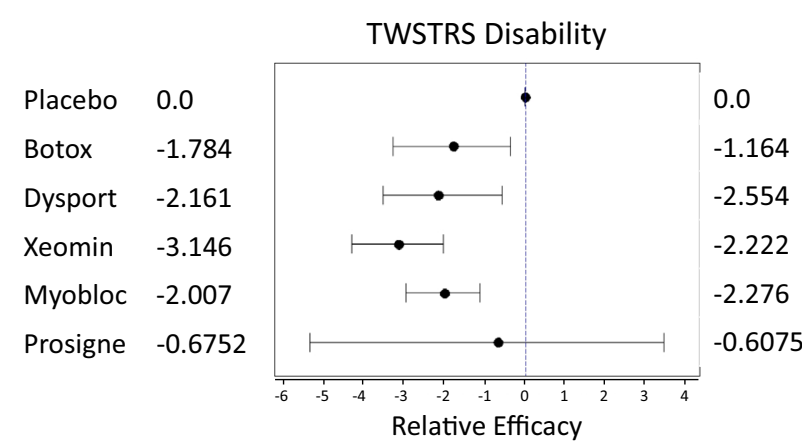

randomization, which is a key factor when comparing several interventions [23].

Dysphagia and injection site pain were the most frequently reported adverse events seen across all studies included in the analysis. This was expected as both are known side effects of treatment with BoNT. Dysport, Botox, Xeomin and Myobloc did not demonstrate a statistically significant different incidence rate for the adverse events under investigation. Previous studies have demonstrated an increased occurrence of dysphagia with BoNT serotype B compared with serotype A in the treatment of $\mathrm{CD}(p=0.0005)$ [16], but this was not demonstrated in the MTC.

Overall, the results of this study suggest that both BoNT serotype A and botulinum serotype B treatments for CD provide a similar efficacy to one another at week four, and all but Prosigne are effective compared with placebo. Of the adverse events measured, neither dysphagia nor injection site pain were significantly greater in the treatment or placebo groups.

This MTC demonstrated an extension of traditional meta-analysis by including multiple different pair-wise comparisons across a range of different interventions. The advantages of Bayesian MTC include the comparison of drugs in the absence of head-to-head data; probability statements that one drug is better (e.g., more efficacious, safer) than another or not; and probability calculations that one drug is best (rank-order the interventions) or that all are similar. Hence, MTCs can provide useful information for (medical) decision-making.

\section{Study limitations}

This analysis was based on published clinical results in the public domain. Conclusions from this study are subject to publication bias which may exist in pharmaceutical clinical research. Furthermore, due to the limited number of available trials, this study only compared the main effects of exposure to different treatments. Other contributing factors, such as dosing, formulation and patient characteristics cannot be explored explicitly. There is no uniformly accepted dosing conversion ratio between the different toxins. Large well-designed head-to-head clinical trials are needed to generate reliable information for patients switching between these treatments. Our analysis used a random effect method to compensate for these confounders. Adverse events investigated in this study were selected based on the availability of published data. Some other interesting safety events, such as neck weakness, were not included due to insufficient data.

\section{Compliance with ethical standards}

Conflicts of interest This work was funded by Ipsen Biopharmaceuticals, Inc. Dr. Han and Dr. Stevens are paid consultants. Dr. Dashtipour and Dr. Mari have received compensation/honoraria for services as a consultant or an advisory committee member or speaker from Ipsen Biopharmaceuticals, Inc. Dr. Hauser is an independent contributor without any financial incentive for the research and development of the current manuscript. He had another unrelated consulting engagement with Ipsen in 2013.

Ethical standards Ethics approval and informed consent are not applicable as the manuscript does not contain clinical studies or patient data that has not been previously published.

Open Access This article is distributed under the terms of the Creative Commons Attribution 4.0 International License (http://crea tivecommons.org/licenses/by/4.0/), which permits unrestricted use, distribution, and reproduction in any medium, provided you give appropriate credit to the original author(s) and the source, provide a link to the Creative Commons license, and indicate if changes were made.

\section{References}

1. Dashtipour K, Lew M (2012) Cervical dystonia. In: Stacy M (ed) Handbook of dystonia, 2nd edn. CRC Press, Boca Raton, pp 144-158

2. Jankovic J, Leder S, Warner D, Schwartz K (1991) Cervical dystonia: clinical findings and associated movement disorders. Neurology 41:1088. doi:10.1212/WNL.41.7.1088

3. ESDE (2000) A prevalence study of primary dystonia in eight European countries. J Neurol 247:787-792

4. Jankovic J, Tsui J, Bergeron C (2007) Prevalence of cervical dystonia and spasmodic torticollis in the United States general population. Parkinsonism Relat Disord 13:411-416. doi:10.1016/ j.parkreldis.2007.02.005 
5. Nutt JG, Muenter MD, Aronson A et al (1988) Epidemiology of focal and generalized dystonia in Rochester, Minnesota. Mov Disord 3:188-194. doi:10.1002/mds.870030302

6. Claypool DW, Duane DD, Ilstrup DM, Melton LJ (1995) Epidemiology and outcome of cervical dystonia (spasmodic torticollis) in Rochester, Minnesota. Mov Disord 10:608-614. doi:10. 1002/mds.870100513

7. Defazio G, Jankovic J, Giel JL, Papapetropoulos S (2013) Descriptive epidemiology of cervical dystonia. Tremor and other hyperkinetic movements (New York, NY), 3. http//tremorjournal.org/article/view/193

8. Dressler D, Paus S, Seitzinger A et al (2013) Long-term efficacy and safety of incobotulinumtoxinA injections in patients with cervical dystonia. J Neurol Neurosurg Psychiatry 84:1014-1019. doi:10.1136/jnnp-2012-303608

9. Benecke R, Jost WH, Kanovsky P et al (2005) A new botulinum toxin type A free of complexing proteins for treatment of cervical dystonia. Neurology 64:1949-1951. doi:10.1212/01.WNL. 0000163767.99354.C3

10. Comella CL, Jankovic J, Truong DD et al (2011) Efficacy and safety of incobotulinumtoxinA (NT 201, XEOMIN, botulinum neurotoxin type A, without accessory proteins) in patients with cervical dystonia. J Neurol Sci 308:103-109. doi:10.1016/j.jns. 2011.05.041

11. Lew MF, Adornato BT, Duane DD et al (1997) Botulinum toxin type B: a double-blind, placebo-controlled, safety and efficacy study in cervical dystonia. Neurology 49:701-707

12. Truong D, Duane DD, Jankovic J et al (2005) Efficacy and safety of botulinum type A toxin (Dysport) in cervical dystonia: results of the first US randomized, double-blind, placebo-controlled study. Mov Disord 20:783-791. doi:10.1002/mds.20403

13. Albanese A, Asmus F, Bhatia KP et al (2011) EFNS guidelines on diagnosis and treatment of primary dystonias. Eur J Neurol 18:5-18. doi:10.1111/j.1468-1331.2010.03042.x

14. Simpson DM, Blitzer A, Brashear A et al (2008) Assessment: botulinum neurotoxin for the treatment of movement disorders (an evidence-based review): report of the Therapeutics and Technology Assessment Subcommittee of the American Academy of Neurology. Neurology 70:1699-1706. doi:10.1212/01. wnl.0000311389.26145.95

15. Jankovic J (2006) Botulinum toxin therapy for cervical dystonia. Neurotox Res 9:145-148. doi:10.1007/BF03033933

16. Comella CL, Jankovic J, Shannon KM et al (2005) Comparison of botulinum toxin serotypes A and B for the treatment of cervical dystonia. Neurology 65:1423-1429. doi:10.1212/01.wnl. $0000183055.81056 .5 \mathrm{c}$

17. Brashear A, Lew M, Dykstra D (1999) Safety and efficacy of NeuroBloc (botulinum toxin type B) in type A-responsive cervical dystonia. Neurology 53:1439-1446

18. Brin MF, Lew MF, Adler CH et al (1999) Safety and efficacy of NeuroBloc (botulinum toxin type B) in type A-resistant cervical dystonia. Neurology 53:1431-1438. doi:10.1212/WNL.53.7.1431

19. Pappert EEJ, Germanson T (2008) Botulinum toxin type B vs. type $\mathrm{A}$ in toxin-naïve patients with cervical dystonia: randomized, double-blind, noninferiority trial. Mov Disord 23:510-517. doi: $10.1002 / \mathrm{mds} .21724$

20. Benecke R, Hauschke D, Roggenkämper P (2013) Incobotulinum/INS;toxin/INS;A demonstrated therapeutic equivalence to onabotulinum/INS;toxin/INS;A in the treatment of blepharospasm and cervical dystonia. J Neurol Sci 333:e120. doi:10.1016/j.jns.2013.07.402

21. Jost WH, Blumel J, Grafe S (2007) Botulinum neurotoxin Type A free of complexing proteins (XEOMIN) in focal dystonia. Drugs 67:669-683. doi:10.2165/00003495-200767050-00003

22. Quagliato EMAB, Carelli EF, Viana MA (2010) A prospective, randomized, double-blind study comparing the efficacy and safety of type a botulinum toxins botox and prosigne in the treatment of cervical dystonia. Clin Neuropharmacol 33:22-26. doi:10.1097/WNF.0b013e3181c46f48

23. Jansen JP, Crawford B, Bergman G, Stam W (2008) Bayesian meta-analysis of multiple treatment comparisons: an introduction to mixed treatment comparisons. Value Health 11:956-964. doi:10.1111/j.1524-4733.2008.00347.x

24. Eddy DM, Hasselblad V, Shachter R (1990) An introduction to a bayesian method for meta-analysis: the confidence profile method. Med Decis Mak 10:15-23. doi:10.1177/0272989X9001000104

25. Higgins JP, Whitehead A (1996) Borrowing strength from external trials in a meta-analysis. Stat Med 15:2733-2749. doi:10. 1002/(SICI)1097-0258(19961230)15:24<2733:AID-SIM562>3. $0 . \mathrm{CO} ; 2-0$

26. Hasselblad V (1998) Meta-analysis of multitreatment studies. Med Decis Mak 18:37-43. doi:10.1177/0272989X9801800110

27. Dominici F, Parmigiani G, Wolpert RL, Hasselblad V (1999) Meta-analysis of migraine headache treatments: combining information from heterogeneous designs. J Am Stat Assoc 94:16

28. Parmigiani G (2002) Modeling in medical decision making : a Bayesian approach. Wiley, Chichester

29. Comella CL, Stebbins GT, Goetz CG et al (1997) Teaching tape for the motor section of the Toronto Western Spasmodic Torticollis Scale. Mov Disord 12:570-575. doi:10.1002/mds. 870120414

30. Jost WH, Hefter H, Stenner A et al (2013) Rating scales for cervical dystonia: a critical evaluation of tools for outcome assessment of botulinum toxin therapy. J Neural Transm 120(3):487-496. http://doi.org/10.1007/s00702-012-0887-7. Accessed 26 Jan 2016

31. Ramirez-Castaneda J, Jankovic J, Comella C, Dashtipour K, Fernandez HH, Mari Z (2013) Diffusion, spread, and migration of botulinum toxin. Mov Disord 28(13):1775-1783

32. Chen JJ, Dashtipour K (2013) Abo-, inco-, ona-, and rima-botulinum toxins in clinical therapy: a primer. Pharmacotherapy 33:304-318. doi:10.1002/phar.1196

33. Ramirez-Castaneda J, Jankovic J, Comella C et al (2013) Diffusion, spread, and migration of botulinum toxin. Mov Disord 28:1775-1783. doi: $10.1002 / \mathrm{mds} .25582$

34. Lu G, Ades AE (2004) Combination of direct and indirect evidence in mixed treatment comparisons. Stat Med 23:3105-3124. doi:10.1002/sim. 1875

35. Ades AE, Sculpher M, Sutton A et al (2006) Bayesian methods for evidence synthesis in cost-effectiveness analysis. Pharmacoeconomics 24:1-19. doi:10.2165/00019053-200624010-00001

36. Moher D, Liberati A, Tetzlaff J, Altman DG (2009) Preferred reporting items for systematic reviews and meta-analyses: the PRISMA statement. PLoS Med 6:e1000097. doi:10.1371/journal. pmed.1000097

37. Hozo SP, Djulbegovic B, Hozo I (2005) Estimating the mean and variance from the median, range, and the size of a sample. BMC Med Res Methodol 5:13. doi:10.1186/1471-2288-5-13 